\author{
VII International Forum on Teacher Education
}

\title{
Aesthetic Education of Bachelors by Means of Information Technologies
}

\author{
Alexandra Zh. Ovchinnikova* (a), Maria V. Lazareva (b), Tatiana A. Solovyeva \\ (c), Olga V. Avramenko (d)
}

(a), (b) Lipetsk State Pedagogical University named after P. P. Semenov-Tyan-Shansky, 398020, Lipetsk (Russia), 42 Lenina Street, dok54@mail.ru

(c) Pskov State University, 180000, Pskov (Russia), 2 Lenin Square

(d).Elets State University named after I.A. Bunin, 399770, Elets (Russia), 28 Kommunarov Street

\begin{abstract}
The relevance of the study is due to the need of using forms integrating modern world achievements in the theory and aesthetic education of bachelors in a new individual-group format. The aim of the study is theoretically justify and implement the directions of using information technologies in aesthetic education of bachelors. Research methods: a) theoretical: analysis, interpretation; b) empirical: questionnaire, pedagogical experiment; c) mathematical: the criterion of angular transformation of Fisher (280 people). The article theoretically substantiates the possibilities of using information technologies in aesthetic education of bachelors. New knowledge about their implementation in the following directions has received: 1) determining cultural foundations of aesthetic education of bachelors, 2) integrative processes in the understanding of artistic images; 3) value-meaning understanding of art based on subjectobject reflection of reality. The criterion of forming aesthetic education of bachelors (motivational, figurative, valuemeaning, creative) and levels are determined: high, figurative, low; the relationship between possession of information technologies and aesthetic education of bachelors is established. The practical significance of the results of the study is using diagnostic techniques, information technologies in aesthetic education of bachelors. Aesthetic education of bachelors should begin with determining its main components and introducing modern information technologies. It is necessary to use several complementary techniques to determine the criterion of using information technologies.
\end{abstract}

Keywords: aesthetic education, bachelor, information technologies, criterion, techniques, levels.

C) 2021 Alexandra Zh. Ovchinnikova, Maria V. Lazareva, Tatiana A. Solovyeva, Olga Avramenko

This is an open access article distributed under the terms of the Creative Commons Attribution License (CC BY 4.0), which permits unrestricted use, distribution, and reproduction in any medium, provided the original author and source are credited.

Published by Kazan federal university and peer-reviewed under responsibility of IFTE-2021 (VII International Forum on Teacher Education) 


\section{Introduction}

The problem of aesthetic education of bachelors is one of the important nowadays. It is connected with the influence of art on the person, on its attitude to nature, the world, the person who can create and spread spiritual values. It is undeniable that information technologies have an increasing influence on the introduction of bachelors to art and culture. These technologies allow broadcasting of modern achievements in culture and art of world importance in a new information format with the help of the computer.

Understanding these principles requires formation skills of bachelors to use modern information technologies which allow forming communicative and research skills, to search information in the world information space, in the Internet, to use ready-made training programs; differentiate learning process, and use software, software and hardware, and technical means.

However, the realization of main areas of aesthetic education of bachelors through information technologies causes certain difficulties which are shown: 1) in the absence of live contact affecting socialization of the personality; 2) in depending the impact of art on the personality from the quality of Internet; 3) in decreasing mental activity associated with the fact that the student often received readymade information from the Internet without thinking about its contents.

\section{Purpose and objectives of the study}

The study was aimed to theoretically provide and implement the main areas of using information technologies in aesthetic education of bachelors. Implementation of this goal requires solving the following tasks of the study:

-to clarify the content of concepts «aesthetic education of bachelors," information technologies;

-to determine criterion and levels of aesthetic education of bachelors by means of information technologies;

-to determine the main areas of aesthetic education by means of information technologies.

\section{Literature review}


Theoretical understanding of aesthetic education of bachelors is based on the analysis of ideas of native and foreign scientists about: cultural foundations of aesthetic education (Burov, 1975; Losev, 1976); integrative processes in the comprehension of art (Lazareva, Lazarev \& Ovchinnikova, 2019; Savenkova, 2018); value-meaning concept of the culturally-based personality (Bakhtin, 1976); aesthetic attitude of the personality to reality and art based on subject-object interaction (Pechko, 2020). These areas have conceptual basis and claim to disclose the content of the concepts "artistic" and "aesthetic" highlighting general and special in them. However, this approach in the educational process of bachelors is developed least of all.

The ratio of such categories as artistic and aesthetic is considered from three points of view now:1) the content of the concepts "aesthetic" and "artistic" is identified (Burov, 1975); 2) artistic is the part of aesthetic, that is artistic values are associated with aesthetic and ideological values of the personality (Musat, 2015); 3) artistic and aesthetic have common points of contact (Pechko, 2020).

In the article, the authors adhere to the third point of view. The category "aesthetic" can be considered more broadly than the category "artistic" if it is determined from the point of view of social existence and aesthetic categories, and "artistic" is presented wider than aesthetic in the subject's creative activities. Each of these concepts integrating reveals certain aspects of knowledge of the world and education qualities of the personality complementing each other. Based on this position, aesthetic education is determined as the process of purposeful influence of art on the ability of bachelors to feel, perceive, understand and create from the perspective of aesthetic categories and artistic activities.

In accordance with this definition, the following structural components were highlighted: motivational, including motives, needs and orientations of bachelors to aesthetic activities; figurative-meaning, characterizing expressive features in creating image and understanding its meaning and creative representing original, associative and unique creation of image. Their content is revealed on the basis of using information technologies as guides to the world art culture.

Comparative analysis of the concepts "information technologies" given by Kuzovlev and Faustova (2008) and Agibalova and colleagues (2020), allowed to determine this concept as the process of functioning components based on the combination of methods, means and forms of collecting, processing, storage and transmission information about the nature of artistic-aesthetic phenomena.

Introduction the computer into information sphere is the feature of information technology.

It allows to make the perception works of art brighter and more emotional, to increase speed and depth of assimilation aesthetic knowledge, carry out distance education of students. Using information technologies 
involves formation skills to work with pedagogical software tools, including search and exchange of information; create multimedia presentations, develop research projects, web quests, TIPS (theory of inventive problem solving), case-study and others (Kuzovlev \& Vaustova, 2008); carry out feedback on such platforms as Webinar, Zoom, Skype, Google, Meet, Discord, Microsoft Teams and TrueConf (Startedtsova, Akutina \& Shchelina, 2020).

\section{Methodology}

Methodological basis of the study is cultural approach based on the understanding of culture as the phenomenon related to cultural and valuable self-reliance of the personality (Pechko, 2020); information and semiotic model of culture (Bakhtin, 1976; Losev, 1976) by sociocultural development of art (Lee, 2019), integrated essence of aesthetic education (Lazareva, Lazarev \& Ovchinnikova, 2019; Lajevic, 2013; Savenkova, 2018).

The study was based on theoretical methods (analysis, generalization, and interpretation); empirical methods (questioning, testing, pedagogical experiment), mathematical methods (Criteria $\varphi^{*}$ - Fisher's angular transformation).

The empirical phase of the research was conducted in the 2020-2021 academic year. It was attended by 280 respondents of the 3-d and 4-th courses of Lipetsk State Pedagogical University named after P.P. Semenov-Tian-Shansky, Elets State University named after I.A. Bunin, Pskov State University. Among them: 140 students of experimental group (EG) and 140 students of control group (CG).

The study was carried out in three stages. At the first stage theoretical analysis of literature on the problem of the study was realized; its purpose and methods were determined; the content of the concept "aesthetic education of bachelors" was clarified; the specifics of information technologies were determined.

At the second stage, the final and forming stages of the experiment on aesthetic education of bachelors were carried out by means of information technologies. At the third stage, quantitative and qualitative analysis of the results at the present and control stages of the experiment,mtheir interpretation and formulation of the main conclusions were presented.

\section{Results}

The purpose of the present stage of the research is to determine the extent of aesthetic education of bachelors and their knowledge of information technologies. 
The tasks of the study:

1) to determine the criterion and levels of aesthetic education of bachelors ;

2) to reveal the extent of possessing information technologies by bachelors;

3) highlight the difficulties that students face in the process of using information technologies.

Solving the first problem of the research allowed to determine the following criterion of aesthetic education of bachelors: motivational, figurative and creative. Specific diagnostic techniques have been developed or applied to each criterion. The results were rated on the scale: 3 points high level, 2 points average level, 1 point low level on each trait.

The motivational criteria included two indicators: 1) necessity for bachelors to study art; 2) necessity to use information technologies.

The authors' diagnosis of aesthetics was developed to the first indicator. It allowed to determine the place of art in the student's life; their preferences in art styles and genres. The following questionnaire was offered to the bachelors.

1. What place does art occupy in your life: 1) insignificant, 2) significant, 3) gives the opportunity to relax, 4) helps to understand the meaning of life, 5) valuable to all little by little.

2. Name: a) art styles that you prefer: 1) classicism, 2) romanticism, 3) realism, 4) impressionism, 5) modernism, 6) avant-garde, 7) symbolism, 8) pop-art.

Analysis of the results of the study according to the first indicator shows that art occupies a small place in the life of 48 bachelors (34.3\%) EG and in the life of 51 bachelors (36.4\%) CG; it has a significant place in the life of 32 bachelors (22.9\%.) EG and in the life of 34 bachelors (24.3\%) CG; 29 bachelors get a chance to rest (20.7\%) EG and 26 bachelors (8.6\%) CG; art helps 19 bachelors to understand the meaning of life (13.6\%) EG and 19 bachelors (13.6\%) CG; 12 bachelors value it a little bit (8.5\%) EG and 10 bachelors $(7.1 \%) \mathrm{CG}$.

53 bachelors EG (37.9\%) and 55 bachelors (39.3\%) CG choosing art styles called classical art and gave examples from literature, fine art and music works; 10 bachelors (7.1\%) EG and 12 bachelors (8.6\%) CG - 
romanticism; 35 bachelors (25.0\%) EG and 34 bachelors (24.3\%) CG - realism; 14 bachelors(10.0\%) EG and 10 bachelors (7.1\%) CG - impressionism; 10 bachelors (7.1\%) EG and 8 bachelors (5.8\%) CG - avantgarde; 16 bachelors (11.4\%) EG and 18 bachelors (12.9\%) CG - symbolism; 2 bachelors (1.4\%) EG and 3 bachelors $(2.1 \%) \mathrm{CG}$ - pop-art.

Method of an unfinished sentence is offered as the second indicator: Using information technologies in aesthetic education of bachelors is important.

The second indicator results: 42 bachelors (30.0\%) EG and 44 bachelors (31.4\%) CG believed that information technologies are a motivating factor that makes art and aesthetic education of bachelors interesting; 38 bachelors (27.1\%) EG and 35 bachelors (25.0\%) CG associated them with visibility; 23 bachelors (16.4\%) EG and 27 bachelors (19.3\%) CG suggested to use them for individualization and differentiation of aesthetic perception of art works; 20 bachelors (13.3\%) EG and 23 bachelors (16.4\%) CG noted the possibility of deeper understanding the meaning of the work; 17 bachelors (12.1\%) EG and 11 bachelors (7.9\%) CG marked more defects than the advantages of using information technologies. Analyzing the data on the motivational criteria the following results were received: 22 bachelors (15.7\%) EG and 25 bachelors (17.9\%) CG were at the high level; 79 bachelors (56.4\%) EG and 81 bachelors (57.9\%) CG were at the average level; 39 bachelors (27.9\%) EG and 34 bachelors (24.2\%) CG were at the low level

Figurative criterion was determined by the following indicators:

1) ability to vivid description of images, their expressive means having an asemantic load;

2) understanding based on perceived images the meaning of the work and its main idea;

3) using information technologies in transmission or creating the image.

Bachelors were invited to describe the images of the following works of art: I.A. Bunin's poem "Twilight", I.I. Levitan's "Over eternal peace" and the musical work "Thinking" by P.I. Tchaikovsky, to identify the means of expressiveness, creating the image from the point of view of the author, a performer and a critic, to determine the main idea of the work, to create an expressive image of this work with the help of information technologies (by choice).

The results of this diagnosis showed that the aesthetically significant properties to describe the image were: 
- color (a grey cloud), light shades (light blue water) and dark shades (dark bare rocks), aesthetic characteristics of color properties;

- brightness (sparkling), warmth and coldness (golden clouds, cold mist); - form, line (mixed twigs), magnitude (mighty look);

- the movement including rhythm, dynamics, statics (the fog is sliding slowly and evenly, everything froze);

- aesthetic characteristics of objects conveying different states ("the surf is buzzing ominously," "harsh view"; "night coming down from the mountains, as if to the temple," "a gloomy chorus of birds"); certain states (peace, agitation and passion).

From the point of view of the author and the listener the main idea through the description of the images was highlighted by 23 bachelors (16.4\%) EG and 25 bachelors (17.9\%) CG; it was difficult for 41 bachelors (29.3\%) EG and for 45 bachelors (32.1\%) CG to determine it; 47 bachelors (33.6\%) EG and 44 bachelors (31.4) CG understood the role of object expressiveness in determining the meaning of the work; The value of image-symbol was determined by 19 bachelors (13.6\%) EG, 18 bachelors (12.9\%) CG; comparisons, metaphors, impersonations were most clearly manifested by 10 bachelors (7.1\%) EG and 8 bachelors $(5.7 \%)$ CG. Students offered following information technologies: presentations, web quests, games to transmit expression of image.

Analysis of the results of the study revealed three levels: high level of 25 bachelors (17.8\%) EG and 27 bachelors (19.3\%) CG; average level of 69 bachelors (49.3\%) EG and 71 bachelors (50.7\%) CG; low level of 46 bachelors (32.9\%) EG and 42 bachelors (30\%) CG.

The creative criterion included the following indicators:

- originality, i.e. aesthetically valuable novelty, brightness and capacity of the image;

- aassociativity - the presence of close and distant associations that arise in connection with the perception of the image of the work;

- fluency - ability to create multiple ideas;

- flexibility - ability to make extensive use of existing experience, to explore quickly subjects in new relationships and links.

Modified methods of E. P. Torrens, E. M. Torshilova were used to determine the levels of this criterion. 
Bachelors were asked to create a fantasy image, draw it and make up the name for it. The scale of assessments: the appearance of images depending on: (a) the name or description of the objects depicted in the works of art - 0.25 points; b) means of expressiveness - 0.5 points; c) transmission the state of nature or a hero - 0.75 points; d) creating character-images based on the unity of content and form -1 point. The research highlighted three levels: high level of 10 bachelors (7.1\%) EG and 7 bachelors (5.0\%) CG; average level of 92 bachelors (65.7\%) EG and 98 bachelors (70\%) CG; low level of 38 bachelors (27.1\%) EG and (25\%) CG.

The second task revealed the following difficulties in the use of information technologies: transmission of the information; making presentations according to the developed rules; possessing research methods; using ICT (information computer tools). In this regard, an algorithm of using information technologies has been developed.

At the formative stage of the experiment the following areas of aesthetic education of bachelors by means of information technologies were determined and implemented:

1) awareness of the cultural foundations of art;

2) highlighting integrative processes in the understanding of artistic images based on the interaction of art forms;

3) organization value-meaningful understanding of images of art.

This process was carried out in the following disciplines: "Forming primary schoolchildren aesthetic feelings in the process of integrating the arts", "Art and aesthetic education of primary school children by means of regional culture," and "Symbolism of arts in the aesthetic development of primary school children." Using information technologies involved forming skills to work with pedagogical software tools including search and exchange of information, creation of multimedia presentations, development of research projects, web quests, TIPS (theory of inventive problem solving), case-study and others; carry out feedback on the following platforms: Vebinar, Zoom, Skype, Google, Meet, Discord, Microsoft Teams and TrueConf.

When passing the themes to each component of the aesthetic education of bachelors (motivational, figurative and creative) and corresponding to its criterion (motivational, figurative and creative) the appropriate tasks related to the use of information technologies were selected.

For example, a motivational component was approached by tasks related to TIPS (theory of inventive problem solving) technologies, debates: "Will beauty save the world?" 
Particular attention was paid to the competent design of presentations in Power Point which required a single style of design slides, ratio of basic and supporting information, competent design of headlines and subtitles; background, created due to the associations arising when creating an image; no more than three colors: for background, headline, text and their competent combination; animated effects should be subordinated to the goal; a laconic and well-structured text; competent using fonts, ways of selection.

Relevant tasks and information technologies were selected for different criterion (figurative-meaning component). Thus, when learning themes: "Art image as the basis of understanding the specifics of art", "Content and structure of aesthetic feelings in aesthetic education," "Aesthetic categories," "The sign and the symbol as means of understanding art," and "Styles and genres of art". Bachelors were offered web quest "The Road to the World of Fiction", an oral magazine "Noosphere" performed in Microsoft Office Publisher, a web quest "The road to the world of Fantasy", research projects: "Beautiful and ugly in the work of W. Eco," "Why does the man need beauty?", art projects: "New Year" and "Maslenitsa."

A special place was given to training telecommunications projects. Their specificity was that they provided studying an aesthetic object, regional culture in various cities in Russia and abroad. This approach allowed revealing the trends of aesthetic education of bachelors. The example is a joint project between Lipetsk State Pedagogical University and Pskov State University on the theme: "Symbolism of Russian folk art in different regions." Such project involved multiple systematic observations of regional cultural objects, their comparison. It revealed peculiarities of folk art depending on the habitat, cultural traditions of the region and development of folk crafts.

To the creative criterion (creative component) tasks for creating videos, cartoons in TupiTube were selected. They envisaged using information environment, personal information space of students in which activities of students in the course of learning and practical activities were recorded.

The control stage of the experiment to determine the effectiveness of the implementation of information technologies in aesthetic education according to the same criterion and methods was conducted in April 2021. The quantitative and qualitative analysis results of the experimental group (EG) at the control stage showed positive dynamics on all criterions by comparison with the current stage and control group (CG). Comparative results are presented in Table 1 and Figure 1.

Comparative analysis of control and stating stages of the experiment showed that in the EG at the control stage the results at a high level increased according to the motivational criterion by 4.2 times; by 2.9 timesin imagery; and by 4.4 times in creative criterion. 
Angular coefficient of Fisher's transformation according to the motivational criterion was $\phi$-emp 7.594; according to the figurative criterion it was $\phi$-emp q 5.339; according to the creative criterion it was $\phi$ emp.q 4.561. The resulting empirical values $\phi$ are in the area of significance. HO is rejected (axis of significance is $1.64-2.31$ ) (Table 1).

Table 1. Levels of aesthetic education of bachelors by means of information technologies

\begin{tabular}{|c|c|c|c|c|c|}
\hline \multirow[t]{2}{*}{ Criteria } & \multirow[t]{2}{*}{ Levels } & \multicolumn{2}{|l|}{ EG } & \multicolumn{2}{|l|}{ CG } \\
\hline & & $\begin{array}{l}\text { Before } \\
\text { training \% }\end{array}$ & $\begin{array}{l}\text { After } \\
\text { training \% }\end{array}$ & $\begin{array}{l}\text { Before training } \\
\%\end{array}$ & $\begin{array}{c}\text { After } \\
\text { training \% }\end{array}$ \\
\hline & high & 15,7 & 65,9 & 17,9 & 32,2 \\
\hline \multirow{2}{*}{ Motivational } & average & 56,4 & 34,1 & 57,9 & 58,9 \\
\hline & low & 27,9 & - & 24,2 & 8,9 \\
\hline \multicolumn{6}{|l|}{$\varphi^{*}{ }_{\mathrm{emp}}=7.594$} \\
\hline & high & 17,9 & 53,4 & 19,3 & 27,2 \\
\hline \multirow[t]{2}{*}{ Figurative } & average & 49,2 & 36,3 & 50,7 & 59,4 \\
\hline & low & 32,9 & 10,3 & 30,0 & 13,4 \\
\hline \multicolumn{6}{|l|}{$\varphi{ }^{*}{ }_{\mathrm{emp}}=5.339$} \\
\hline & high & 6,7 & 30,8 & 4,0 & 8,0 \\
\hline \multirow{2}{*}{ Creative } & average & 59,1 & 57,0 & 74,0 & 70,0 \\
\hline & low & 34,2 & 9,3 & 22,0 & 22,0 \\
\hline
\end{tabular}

While in the CG on the motivational criterion the results at the control stage of the experiment compared to the present stage increased by 1.8 times, $\varphi$-emp 2.312. The received empirical value $\varphi$ is in the area of significance. H0 is rejected; in figurative by 1.7 times, $\varphi$-emp is 1.351 . The received impirical value $\varphi$ is in the insignificance zone. H1 is rejected; in creative by 2 times the $\varphi$ 'emp q 1.209. Received empirical value $\varphi$ is in the zone of insignificance. H1 is rejected. The dynamics of the results of the research in EG.

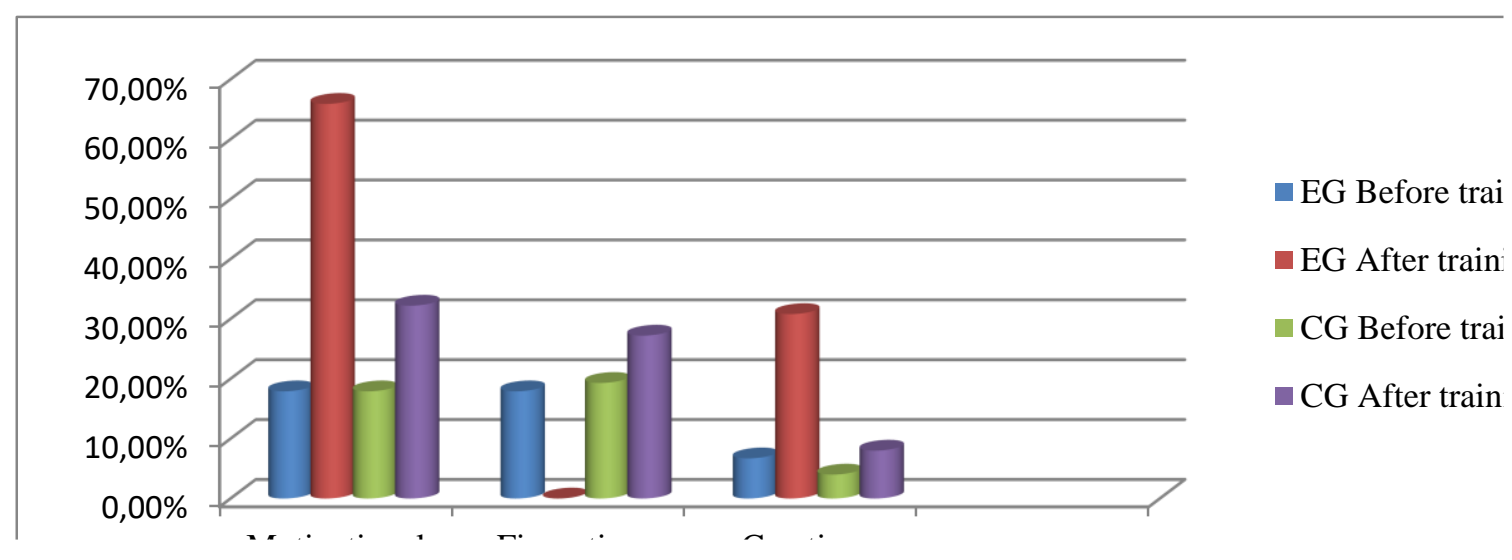

Figure 1. The dynamics of the results of study in EG and CG before and after training at a high level 
Thus, according to the study it was proved that there is direct correlation between using information technologies and aesthetic education of bachelors.

\section{Discussion}

The study of psychological and educational literature allows to state inadequacy of justification the concept aesthetic education of bachelors by aesthetic and psychological-educational literature. However, there are some areas, such as: studying this phenomenon on the basis of socio-cultural information and semiotic model; integrated essence of aesthetic education was examined in detail by Burov (1976), Bakhtin (1979), Lee (2019) and Pechko (2020).

\section{Conclusion}

The research found that implementation of the main areas of aesthetic education of bachelors (awareness of cultural foundations of art; allocation integrative processes in understanding artistic images based on the interaction of art forms; organization of value-meaningful understanding images of art) is more effective when using information technologies expanding boundaries of knowledge through network interaction and digital technologies.

The study made it possible to recommend teachers to use each component or criterion of aesthetic education of bachelors following information technologies: TRIS technologies, debates, web quests, and research and telecommunication projects.

Analysis of the results of the research allowed revealing the criterion for forming aesthetic education of bachelors by means of information technologies (motivational, figurative and creative) and levels: high, average, low. The effectiveness of using information technologies in aesthetic education of bachelors was proved by the methods of mathematical statistics using the angular conversion factor of R.Fisher.

\section{References}

Agibova, I. M., Kulikova, T. A., Poddubnaya, N. A., \& Fedina, O. V. (2020). Development of digital competence of a future teacher in the context of informatization and digitalization of modern teacher education https. ARPHA Proceedings (3), 13-26. 
Bakhtin, M. M. (1979). Aesthetics of verbal creativity. Moscow: Ripol Classic.

Begantsova, I. S., Akutina S. P., \& Shchelina T. T. The Question of students' preparedness for studying in the digital educational. ARPHA Proceedings (3), 207-218.

Burov, A. I. (1975). Aesthetics: Problems, Disputes. Moscow: Iskusstvo.

Kuzovlev, V. P., \& Faustova, N. P. (2008). Application of information and telecommunication technicians in the educational process of school: educational manual. Yelets, Bunin Yelets State University.

Lazareva, M. V., Lazarev, B. N., \& Ovchinnikova, A. Zh. (2019). The implementation of integrated technology in teaching junior school students. Bulletin of the Cherepovets State University, 3(90), $160-168$.

Lajevic, L. (2013). Arts Integration: What is Really Happening in the Elementary Classroom? Journal for Learning through the Arts: Research Journal on Arts Integration in Schools and Communities, 9(1), $1-30$.

Lee, L. (2019). Transforming a School through Arts Integration. Edutopuia. Retrieved from: https://www.edutopia.org/article/transforming-school-through-arts-integration

Losev, A. F. (1976). Character Problem and Realistic Art «Text». Moscow: Art.

Musat, R. P. (2015). Artistic world view: aesthetic aspects. Modern problems of science and education, № 2 (part 1), 350-357.

Pechko, L. P (2020). Problems of activation creativity of gifted teenagers in artistic and aesthetic environment: monograph. Moscow: Moscow.

Savenkova, L. G. (2018). Integrated technology humanitarization of education. Humanitarian space, 1, 142-166. 